\title{
El escepticismo profesional del contador público
}

\author{
Professional scepticism of the public accountant
}

\author{
Cetecismo profissional do contador público
}

\section{ARTÍCULO DE REVISIÓN}

\author{
Myrian Hidalgo Achig 1 \\ myrian.hidalgo@utc.edu.ec \\ ORCID: 0002-6582-1657
}

Marcela Vizuete Achig 1

marcela.vizuete@utc.edu.ec

ORCID: 0002-4361-9394

\author{
Milton Hidalgo Achig ${ }^{2}$ \\ m.hidalgo@istvicenteleon.edu.ec \\ ORCID: 0001-5184-3110
}

Lorena Espín 1

lorena.espin2958@utc.edu.ec

ORCID: 0003-4544-7562

\section{${ }^{1}$ Universidad Técnica de Cotopaxi, Ecuador \\ ${ }^{2}$ Instituto Superior Tecnológico Vicente León, carrera de Contabilidad, Ecuador}

Recibido 10 de noviembre 2020 | Arbitrado y aceptado 27 de noviembre 2020 | Publicado en diciembre 2020

\section{RESUMEN}

Los escándalos financieros de los años 80 y 90 en Ecuador, conjuntamente con la crisis financiera actual ha provocado un llamado de atención a los informes recientes de auditorías por parte de las entidades de supervisión, ya que consideran que los auditores independientes deben hacer evidente su escepticismo profesional, pues se constituye en un rasgo esencial que contribuye a la independencia del auditor en la emisión de opiniones de la razonabilidad de la información financiera. La investigación plantea analizar el escepticismo profesional y los elementos que se involucran (atributos, mentalidad, acción) para mejorar la calidad de la auditoria e incrementar la confianza de los usuarios en la información proporcionada por el auditor. La metodología expone un análisis documental, descriptivo - teórico desde la revisión pormenorizada de libros y revistas nacionales e internacionales. Partiendo de los conceptos de auditoría para finalmente describir el escepticismo profesional y su incidencia en la opinión del auditor.

Palabras clave: Auditor; Auditoría; Escepticismo profesional; contador

\section{ABSTRACT}

The financial scandals of the 1980s and 1990s, together with the current financial crisis, have led to a call for attention to recent audit reports by supervisory entities, as they consider that independent auditors should make their professional skepticism more evident, as it is an essential feature that contributes to the independence of the auditor in issuing opinions on the reasonableness of financial information. The research proposes to analyze the professional skepticism and the elements that are involved (attributes, mentality, action) to improve the quality of the audit and increase the trust of users in the information provided by the auditor. The methodology exposes a documentary, descriptive - theoretical analysis from the detailed review of national and international books and magazines. Starting from the audit concepts to finally describe professional skepticism and its impact the auditor's opinion.

Key words: Audit; auditor; professional skepticism 


\section{RESUMO}

Os escândalos financeiros das décadas de 1980 e 1990, juntamente com a atual crise financeira, levaram a uma chamada de atenção para os relatórios de auditoria recentes das entidades de supervisão, pois consideram que os auditores independentes devem tornar mais evidente o seu ceticismo profissional por ser uma característica essencial que contribui para a independência do auditor na emissão de opiniões sobre a razoabilidade das informações financeiras. A pesquisa se propõe a analisar o ceticismo profissional e os elementos que estão envolvidos (atributos, mentalidade, ação) para melhorar a qualidade da auditoria e aumentar a confiança dos usuários nas informações prestadas pelo auditor. A metodologia apresenta uma análise documental, descritiva - teórica a partir da revisão detalhada de livros e revistas nacionais e internacionais. Partindo dos conceitos de auditoria para finalmente descrever o ceticismo profissional e seu impacto na opinião do auditor.

Palavras-chave: Auditor; auditoria; cetecismo profissional

\section{INTRODUCCIÓN}

El escepticismo profesional se constituye en un factor que genera errores al momento de emitir el dictamen el auditor, es así que, durante los años setenta se produjo en Estados Unidos un caso impresionante de fraude, encabezado por los directivos de un fondo de inversión conjuntamente con la actuación de auditores que incurrieron en graves errores como complejo de inferioridad frente a los directivos, confianza ilimitada en los empleados de la compañía, no verificación de operaciones entre filiales y la matriz, la confirmación de saldos de clientes se los realizaba en los locales de la compañía.
Además, de este caso existen 56 casos más de fraudes contables detectados por la SEC en Estados Unidos y, que fueron sancionados, con la intención de descubrir las fallas de los auditores; se determinó que los 10 errores más comunes cometidos por los auditores está relacionado con el escepticismo profesional, cuyo resultó corresponde al $60 \%$, colocándose esta acción en la tercera causa de los fraudes.

\section{MÉTODO}

Las competencias profesionales tienen múltiples facetas, epistemológica, sociológica, política y práctica; por ello reclaman una perspectiva multidimencional e integral de los aprendizajes. La comprensión, el juicio y la movilización de diversos recursos cognitivos, personales, sociales y éticos constituyen la estructura interna de una competencia, así como la capacidad de aprender a aprender, que es esencial para captar su carácter cambiante y evolutivo.

La presente es una investigación documental, que, a través de un análisis metodológico, se orientó al uso racional y practico de la información y recursos disponibles en buscadores, repositorios $\mathrm{y}$ agregadores de artículos como SciELO, Latindex, Google Scholar. La investigación se ejecutó como un proceso sistemático que recolectó, organizó, analizó e interpretó la información, elaborando fichas bibliográficas con la información relevante, pertinente $\mathrm{y}$ significativa para el objeto de estudio. A continuación, se presenta el proceso metodológico empleada planteada por Hurtado (2010): 
Selección y delimitación del tema de estudio.
De esta manera, se plantea la recopilación, identificación de ideas y redacción del documento, para lo cual se revisaron los diferentes aspectos conceptuales planteados por los autores sobre el tema estudiado.

\section{DESARROLLO}

La Federación Internacional de Contadores Públicos (IFAC, 2015), define el escepticismo como "la actitud mental de cuestionamiento, de la validez de la evidencia obtenida y estar alerta a evidencia que contradiga o ponga en duda la confiabilidad de los documentos o representaciones de la parte responsable"

De acuerdo a lo mencionado se puede decir que el escepticismo profesional es un elemento importante de la calidad de trabajo del auditor, y su uso inadecuado expone al profesional a litigios y daños que pueden causar perjuicios en su reputación.

La auditoría juega un papel muy importante en una empresa: refleja su imagen contable, administrativa y operativa, esta se constituye en "un examen sistemático de los estados financieros, registros y operaciones con la finalidad de determinar si están de acuerdo con los principios de contabilidad generalmente aceptados, con las políticas establecidas por la dirección y con cualquier otro tipo de exigencias legales o voluntariamente adoptadas" (Madariaga, 2004, pág. 13). Además, que la Ley de Auditoría de Cuentas (LAC) y su Reglamento mencionan que la auditoria es la actividad que consistente en "la revisión y verificación de las cuentas anuales, así como de otros estados financieros o documentos contables, elaborados con arreglo al marco normativo de información financiera que resulte de aplicación, siempre que aquélla tenga por objeto la emisión de un informe sobre la fiabilidad de dichos documentos que puede tener efectos frente a terceros. (Artículo 1.2). Razón por la cual el servicio de auditoría constituye un apoyo a todos los miembros de la organización pues esta emite opiniones en beneficio de la organización.

Para el desarrollo de este proceso las organizaciones contratan a profesionales 
llamados auditores quienes verifican la información de la empresa para determinar si esta ha cumplido con las normas contables, fiscales y legales durante un periodo de tiempo. Así pues el auditor es una persona capacitada y con la suficiente experiencia para revisar y verificar que los datos contables, administrativos y operativos que la empresa auditada facilita se corresponden realmente con la actividad que ha venido desarrollando.

Hoy en día la labor del auditor va más allá del simple control de cuentas y hoy se valora especialmente su papel como asesor que ayuda a las organizaciones a identificar deficiencias y errores en las diferentes actividades de la empresa, sin embargo, los auditores se han visto inmersos en varios hechos que han puesto entre dicho a la profesión.

A raíz de los escándalos financieros recientes, así como de la crisis financiera global de los últimos años (2008-2009), en informes recientes de inspección de auditorías en diversas jurisdicciones se observa que los reguladores y los organismos de supervisión consideran que los auditores independientes deben hacer más evidente su escepticismo profesional en áreas como: transacciones con partes relacionadas, evaluaciones de negocio en marca y determinación de estimaciones contables, en donde el juicio de la Administración es importante. (Rubio, 2012)

La palabra escepticismo se forma a partir de la raíz "escéptico", que viene de la palabra griega "skeptikos", que significa investigar es "buscar información al cuestionar; preguntar.

La naturaleza crítica de escepticismo profesional es un tema central en el Centro de disuasión y detección de Información Financiera de Fraude de Auditoría de Calidad: Una plataforma de acción (octubre de 2010). En ese informe, la CAQ señaló que el escepticismo es:

...un elemento esencial de la objetividad profesional que se requiere de todos los participantes en la cadena de suministro de información financiera. El escepticismo lo largo de los aumentos de la cadena de suministro no sólo la probabilidad de que se detecte el fraude, sino también la percepción de que se ha detectado el fraude, lo que reduce el riesgo de que el fraude se intentará... Para los auditores internos y externos, el escepticismo es una parte integral de la conducta de sus deberes profesionales, incluyendo la consideración del riesgo de que la administración de controles internos (p. VII)

El importante papel de escepticismo profesional en la práctica de auditoría se evidencia por su importancia a lo largo de las normas de auditoría de los Estados Unidos (por ejemplo, SAS 1 (AICPA, 1997); SAS 82 (AICPA, 1997); SAS 99 (AICPA, 2002)

Las Normas de Auditoría de los Estados Unidos definen al escepticismo como "una actitud que incluye una mente inquisitiva y una evaluación crítica de la evidencia de auditoría" (AICPA, 1997, Sección AU 230.07) (PCAOB, 2006, párr. 7) y que "debe ser ejercido a lo largo del proceso de auditoría" (PCAOB, 2006, párr. 8). el juicio y la acción escépticos están cada vez afectadas por diversos incentivos, rasgos de auditor, y el conocimiento auditor que puedan prevenir, o desalentar, los auditores de actuar en su propio criterio escéptico (Nelson 2009).

En el contexto de fraude, las normas manifiestan que para mantener el escepticismo profesional "requiere cuestionarse continuamente" (IAASB, 2013, Sección A7). Cuando se habla de fuentes de 
evidencia de auditoría, las normas abrazar una postura neutral cuando describen un auditor de escéptica como uno que "no asume que la administración es deshonesta, ni asume la honestidad incuestionable" (AU Sección 230.09).

Una importante consideración al momento de desarrollar auditorias es que este proceso no es mecánico sino al contrario requiere del ejercicio continuo de formulación de juicios y toma de decisiones profesionales. La NIA 200 IASB (2013) señala que "el auditor planificará y ejecutará la auditoría con escepticismo profesional, reconociendo que pueden darse circunstancias que supongan que los estados financieros contengan incorrecciones materiales" (p. 7, apartado15).

Rubio, (2012) señala que:

\begin{abstract}
El escepticismo profesional desempeña una parte integral del conjunto de habilidades del auditor y está estrechamente relacionado con el juicio profesional. Ambos son esenciales para desempeñar una auditoría independiente y son elementos clave que contribuyen a la calidad de la auditoría (p.3).
\end{abstract}

El escepticismo profesional facilita el ejercicio de un adecuado juicio profesional del auditor, especialmente sobre decisiones, respecto a:

- La naturaleza, la oportunidad y el alcance de los procedimientos de auditoría a realizarse.

- La evaluación sobre si se ha obtenido evidencia de auditoría suficiente y competente, o bien, si se requiere hacer trabajo adicional para cubrir adecuadamente los objetivos de las NIA.

- La evaluación de los juicios de la Administración en la aplicación de las NIF aplicables, para la emisión de información financiera.

- Las conclusiones basadas en la evidencia de auditoría obtenida; por ejemplo, al evaluar la razonabilidad de las estimaciones efectuadas y supuestos considerados por la Administración, en la preparación de los estados financieros."

Para Nelson (2009) el escepticismo "se expresa mediante juicios del auditor $\mathrm{y}$ decisiones que reflejan una evaluación acerca del riesgo que una afirmación es incorrecta, condicionando la información disponible por el auditor", este autor establece un modelo relacionado con el escepticismo denominado" (p.4). Quiere decir que los determinantes del escepticismo profesional en el desempeño de la auditoría describe como la evidencia de auditoria se combina con el conocimiento del auditor, rasgos y los incentivos para producir juicios que reflejen el escepticismo, este modelo pone de relieve que dado un juicio que refleja un cierto nivel de escepticismo la sentencia se combina con el conocimiento del auditor, rasgos y los incentivos para producir acciones que reflejen escepticismo profesional.

El modelo de escepticismo definido por Nelson (2009) se encuentra estructurado de acuerdo a las siguientes características:

- En el centro mantiene la idea de que hay una diferencia entre el juicio escéptico y acción escéptico (1)

- La evidencia de entrada que es un elemento probatorio de entrada que contribuye al juicio del auditor (2),

- El conocimiento del auditor, nivel de competencia, es decir, los conocimientos del personal que participa en una auditoría, incluyendo su educación, 
capacitación y experiencia profesional; $y$, otros no conocimientos (rasgos del auditor) características personales de comportamiento del auditor, como son: la actitud y los valores éticos, (3)

- Rasgos son atributos que no son de conocimiento del auditor que puede afectar su escepticismo profesional. (4)

- Incentivos (5)

- Experiencia hace relación a formación y visualización de rasgos como fijo en el momento en que un auditor comienza la formación de auditoría y práctica (7)

Las características definidas en el modelo de Nelson (2009) captan la idea de que los escépticos mantienen una mente abierta y cuestionan las posibles conclusiones, en busca de pruebas, teniendo en cuenta que la evidencia potencial es sesgada, y cuestionándose agresivamente hasta que personalmente llegan a una conclusión.

Por su parte, Hurtt (2010) hace mención a temas relacionados con escepticismo es, señalando que el escepticismo profesional es "una característica individual multidimensional" (p. 149), que considera como característica individual, el escepticismo profesional que puede ser a la vez un rasgo (un aspecto relativamente estable y duradero de un individuo) y también un estado (una condición temporal despertada por variables situacionales), señala además que el escepticismo tiene 6 características: Una mente inquisidora, una suspensión de juicio, la búsqueda del conocimiento (la forma como el auditor examina la prueba); la comprensión interpersonal (aspectos humanos de la auditoría); y, la autoestima y autonomía (capacidad del individuo para actuar sobre la información obtenida).

Hurtt (2010) analiza los rasgos escepticismo sobre la base de las normas de auditoría y la psicología de acuerdo con el entorno de trabajo de auditoría, visualiza el escepticismo profesional como un rasgo más que una respuesta a la auditoría para ello utiliza una escala desarrollada específicamente para medir el nivel de escepticismo profesional del auditor, analiza su impacto en dos comportamientos; valoración de la prueba y la generación de alternativas, su investigación concluye manifestando que: los auditores con mayores niveles de escepticismo profesional se comportan de manera diferente que los auditores sistemáticamente menos escépticos, es decir que cuando los auditores determinan que existen mayores riesgos, se necesitan más pruebas.

\section{DISCUSIÓN}

Desde la perspectiva de la profesión de auditoría, la necesidad de comprender el escepticismo profesional es un problema reconocido por los auditores y los reguladores de mercados financieros, este se constituye en un elemento que incide en la calidad de la auditoría.

Dada la importancia del escepticismo profesional como la base de la profesión de auditoría, la propuesta de investigación se enfoca en el escepticismo profesional del contador público en el desarrollo de la actividad de auditoría financiera, que se ha considerado una de las fuentes de mayores errores en el trabajo de los auditores, para el desarrollo de la investigación se ha considerado establecer un modelo que permita vincular el conocimiento (experiencia, especialización) y los rasgos de personalidad de un contador (capacidad para resolver problemas) con el grado de escepticismo que se manifiesta, a partir de la propuesta de Nelson (2009) que permita mejorar la calidad del trabajo de auditoría. 


\section{CONCLUSIONES}

El escepticismo profesional por parte del contador público es de vital importancia en la independencia de los auditores, además que es exigido por las Normas Internacionales de Aseguramiento y Auditoría, así como por el Manual del Código de Ética para profesionales de la Contabilidad.

El escepticismo profesional es un pilar fundamental que contribuye en la calidad de la Auditoría, ya que permite evaluar eficientemente las aseveraciones de la gerencia acerca de la información financiera basada en una actitud de cuestionamiento vinculado con los principios éticos de la objetividad que guiados en los procesos de aseguramiento le proporcionan la base para emitir una opinión sobre la razonabilidad de la información.

El escepticismo profesional está estrechamente vinculado con los principios éticos de objetividad e independencia del auditor permitiendo incrementar la eficiencia de la auditoria, además, cuestionar la existencia real de una transacción económica, desconfiar de la información hasta que el auditor este satisfecho con la evidencia generada y solicitar el sustento claro de los criterios establecidos.

\section{REFERENCIAS}

Hurtt, K. (2010). Development of a Scale to Measure Professional Skepticism. AUDITING. Journal of Practice \& Theory, 149-171

Hurtado, J. (2010). Metodología de la Investigación. Guía para la comprensión holística de la ciencia. Ediciones Quirón. Caracas, Venezuela

IASB, I. A. (2013). NIA 200. Normas Internacionales de Auditoria. Handbook 2013

IFAC, I. F. (2015). Manual del Código de ética para profesionales de la Contabilidad. EEUU: IFAC

Nelson, M. (2009). Un modelo de revisión de la literatura de escepticismo profesional en auditoría. Auditoria: Un diario de Práctica y Auditoría, 1-34

PCAOB, J. P. (2006). Junta Pública Compañía de Vigilancia de Contabilidad (PCAOB). 2006. El debido cuidado profesional en la El debido cuidado profesional en la ejecucuión de los trabajos, la sección AU 230. Obtenido de Junta Pública Compañía de Vigilancia de Contabilidad (PCAOB). 2006. El debido cuidado profesional en laDisponible en http://pcaobus.org/standards/auditing/ páginas / AU230.aspx

Rubio, A. (07 de 08 de 2012). Escepticismo profesional. En una auditoría de estados financieros. Contaduría Pública. Instituto Mexicano de Contadores Públicos 


\title{
Incidencia de la música y la sensopercepción en niños de 4 años de edad
}

\author{
Impact of music on and sensoperception on 4-year-olds
}

Incidência de música e percepção sensorial em crianças de 4 anos

ARTÍCULO DE INVESTIGACIÓN

Karelys Keiko Cànchica

karelys.canchica@cordillera.edu.ec

canchicakmusics@gmail.com

ORCID: 0000-0002-2707-7839
Karolina Fernanda Bastidas

fernanda-salo.06@hotmail.com

ORCID: 0000-0001-9039-7037

\section{Instituto Tecnológico Universitario Cordillera, Ecuador}

Recibido 20 de noviembre 2020 | Arbitrado y aceptado 12 de diciembre 2020 | Publicado en diciembre 2020

\section{RESUMEN}

La incidencia de la música y la sensopercepción en niños de 4 años de edad es un tema innovador que debe ser analizado y conocido por docentes y todo adulto relacionado con la educación inicial, con el fin de diseñar experiencias de aprendizaje utilizando sentidos para activar el cerebro utilizando como recurso la música. El objetivo de esta investigación fue analizar el nivel de conocimiento de docentes que tienen a su cargo niños de 4 años de edad. Se utilizaron métodos como la investigación descriptiva con un tipo de diseño de campo, a través de la técnica de la observación utilizando como instrumentos de registros descriptivos y encuesta. Se evidenció que las docentes a veces emplean actividades musicales para la rutina diaria mas no para la utilización de la sensopercepción y la música, sin embargo todos están interesadas en recibir capacitaciones para aplicarlas.

Palabras clave: Sensopercepción; música; docentes; niños, educación inicial

\section{ABSTRACT}

The incidence of music and sensoperception in 4-year-olds is an innovative topic that should be analyzed and known to teachers and every adult related to initial education, in order to design learning experiences using sensitdos to activate the brain using music as a resource. The objective of this research was to analyze the level of knowledge of teachers in charge of 4-year-olds. Methods such as descriptive research with a type of field design were used, through the technique of observation using descriptive records and survey as an instrument. It was shown that teachers sometimes employ musical activities for the daily routine but not for the use of sensoperception and music; however, everyone is interested in receiving training to apply them.

Key words: Sensoperception; music; teachers; children, initial education 


\section{RESUMO}

A incidência de música e sensopercepção em crianças de 4 anos é um tema inovador que deve ser analisado e conhecido por professores e adultos relacionados à educação inicial, a fim de projetar experiências de aprendizagem usando sensibilizadores para ativar o cérebro usando a música como recurso. 0 objetivo desta pesquisa foi analisar o nível de conhecimento dos professores responsáveis pelas pessoas de 4 anos. Foram utilizados métodos como pesquisa descritiva com tipo de desenho de campo, por meio da técnica de observação utilizando registros descritivos e levantamento como instrumento. Mostrou-se que os professores às vezes empregam atividades musicais para o cotidiano, mas não para o uso de sensopercepção e música, porém todos estão interessados em receber treinamento para aplicá-los.

Palavras-chave: Sensopercepção; música; professores; crianças, educação inicial

\section{INTRODUCCIÓN}

La presente investigación estudia la realidad entre la incidencia de la música y la sensopercepción utilizada por docentes de educación inicial con niños de cuatro años de edad. La música es un factor ineludible dentro del proceso educativo, es por esta causa que organizaciones a nivel mundial incorporan dentro de sus programas planes musicales para desarrollar en los pequeños el amor por el arte, proporcionando actividades para estimular los sentidos a través de los sonidos.

$\mathrm{Al}$ respecto, el (Fondo para las Naciones Unidas de la Infancia, 2020) (UNICEF) en Costa Rica cuenta con el programa Crecer con la Música desde el año 2008, obteniendo excelentes resultados en los niños que los reciben mejoran áreas de desarrollo como la cognitiva y la socia afectiva la integración y alegría, así como mejorar el sistema auditivo, facilitar la expresión de sentimientos e ideas, ayudar al desarrollo de la memoria. Mejorar las capacidades motrices, ppotenciar las capacidades artístico-creativas favorecer la integración socio-cultural, ampliar y mejorar posibilidades lingüísticas, entre otros

Desde esta perspectiva, UNESCO (2012) sostiene que "es innegable la relación que ésta mantiene con la música, pero el punto de análisis se centra en que se separa la música del aula y se trabaja, como además se entiende la motricidad en Infantil, de manera aislada". (s/p).

En consecuencia, pareciera que el uso de la música en la etapa inicial es además de útil un recurso obligatorio dentro de las destrezas del currículo de educación inicial, sin embargo, siendo la música un recurso ineludible en toda la jornada referente al proceso de enseñanza y aprendizaje en niños de cuatro años, esta es utilizada comúnmente por los maestros para socializar, dar órdenes, hábitos, entre otros.

Una visión sobre el panorama curricular en Ecuador, las actividades musicales parecieran estar siendo subutilizadas por los maestros, al respecto el Periódico La Vanguardia 2019 presenta un artículo donde expresa la poca importancia que se da a las actividades musicales y la sensopercepción en los niños de educación primaria. Señala Alvarado, (2019) “El reconocimiento y valoración del papel que estas enseñanzas desempeñan en la educación global es una de las principales reivindicaciones de los profesionales de la asignatura". Desde esta perspectiva existen muchos autores que coinciden en el hecho del poder que tiene la música para activar potencialidades cognitivas, dicho esto desde el punto de vista del desarrollo cerebral.

A pesar de que organizaciones tan importantes a nivel mundial como la antes mencionada le dan preminencia a este tema, la realidad pareciera ser distinta, los docentes de educación inicial podrían mostrar preocupación 
a la hora de planificar actividades musicales, Sánchez (2005) afirma que:

No es necesario ser especialista en el área de música para trabajar este aspecto, simplemente la/el profesional de la docente debe apropiarse de una serie de herramientas que le van a permitir de manera clara y sencilla mediar este aprendizaje (p. 5).

Es preocupante el hecho de que la música, aunque está relacionada directamente con el proceso formativo de los niños y niñas, está siendo poco utilizado por las docentes en el desarrollo de estrategias metodológicas para estimular el desarrollo integral de los niños, por esta causa se revisan documentos gubernamentales que dictaminan el deber ser en el desarrollo de las actividades en esta área.

Desde esta perspectiva, en Ecuador el Ministerio de Educación (2014) ofrece destrezas que deben ser planificadas por el docente, pero queda a criterio de cada maestro organizar experiencias de aprendizaje utilizando distintas metodologías para lograr tal fin, existiendo variedad de artículos, publicaciones que presentan ideas novedosas para la estimulación a través de la sensopercepción utilizando como recurso la música.

La música es accesible a todo público y debe utilizarse como un recurso necesario para el desarrollo psicológico y social afectando áreas emocionales. Es interesante poder validar que la música tiene un poder universal, en el sentido de poder afectar las áreas cognitivas a través de un aprendizaje vivencial.

El Ministerio de Educación de Ecuador (MINEDUC, 2014) "parte de la visión de que todos los niños son seres bio-psicosociales y culturales, únicos e irrepetibles y los ubica como actores centrales del proceso de enseñanza aprendizaje." (p.16), esto presenta un niño con características distintas, con distintas formas de aprendizaje, por ello, se hace necesaria la preparación del docente en emplear metodologías que conlleven este amplio rango y diversidad de conocimiento, utilizando los distintos canales de aprendizaje para lograr una enseñanza útil y generadora de ideas y disfrute tomando en cuenta que las destrezas es el fin que debemos alcanzar, pero el medio está abierto, disponible y dependerá tanto del conocimiento como de la creatividad del maestro para ejecutarlas.

Floralba y Villacis (2018) realizan un estudio sobre los cambios en plan nacional Ecuatoriano analizando el retiro de la asignatura de educación musical, siendo incluida en el Currículo de educación cultural y artística. La desventaja parte del desconocimiento y la poca consciencia acerca de la importancia de la música en el contexto ecuatoriano no coincide con las teorías de aprendizaje relacionadas con la música y los procesos educativos, las horas destinadas a desarrollar destrezas en los niños no son las adecuadas, Se realiza un análisis de los currículos de otros países reflexionando acerca de la educación musical como referente para el desarrollo de destrezas y habilidades que aportan a la formación integral del ser humano y finalmente, propone algunas perspectivas y desafíos de la educación musical. (Floralba, y Villacis, 2018).

Las evidencias anteriores corroboran la veracidad de la asociación entre las experiencias artísticas musicales y las actividades cognitivas a través de la sensopercepción, considerado que es esencial tomar en cuenta este tipo de experiencias, sin embargo en la cotidianidad pareciera tomarse este arte como un paralelismo asociado a la actividad cognitiva en los niños, siendo este proceso generado por 
destrezas muy bien establecidas en las mallas curriculares, con el propósito de potenciar todas las áreas de aprendizaje, la música tiene la facultad de abordar todos estas habilidades esperadas en los niños de cuatro años puesto que científicamente se ha logrado descubrir que las ondas sonoras tienen un efecto notable en la actividad cerebral.

Sobre las bases de las ideas expuestas queda determinado que los estudios anteriormente referidos tienen basamento teórico sobre la incidencia entre la música y las actividades de sensopercepción, colocando al niño como un ser en crecimiento y desarrollo, que necesita actividades de estimulación apropiadas para su desempeño optimo en todas las áreas de desarrollo.

La presente investigación es dirigida a los niños de cuatro años de edad del Centro Infantil Mario Benedtti ubicado en Quito, Ecuador. Las interrogantes de la investigación surgen de las observaciones realizadas por la coautora de la investigación en su tiempo de Prácticas profesionales en el año 2019, la cual observa y determina la poca actividad musical aplicada al desarrollo de los procesos cognitivos. Por lo que, se plantea la hipótesis hacer de la música favorece los procesos de sensopercepción.

Para tal efecto se presenta este estudio donde en donde se analiza el nivel de conocimiento de los docentes de Educación Inicial sobre la incidencia de la música a través de la sensopercepción en niños de 4 años de edad; además, se busca fundamentar la incidencia de las actividades musicales en el proceso de la; y por último, es analizada la importancia del conocimiento de los docentes de educación inicial sobre las actividades musicales y la sensopercepción en niños de 4 años de edad.

El estudio se apoya en la necesidad e importancia que tiene la sensopercepción en el proceso de enseñanza y aprendizaje para educador y el niño. Esto desarrolla la apropiación de metodologías actualizadas donde el aprendizaje se extienda de forma vivencial, a través de los sentidos y con un recurso útil como lo es la música, se hace necesario que el docente conozca estrategias apropiadas para el uso efectivo de la música activando los canales sensoperceptivos (uso de todos los sentidos) esta actividad abrirá campos neuronales y activará zonas del cerebro al mismo tiempo permitiendo que los usos de las estrategias musicales sean más efectivas ya que el aprendizaje se transmitirá de forma vivencial.

\section{El currículo de Educación Inicial y la sensopercepción}

Atendiendo a estas consideraciones, la elaboración de este documento oficial integra las áreas de desarrollo como factor fundamental para diseñar distintas actividades metodológicas a través de experiencias de aprendizaje o el juego trabajo, formas fundamentales para el desarrollo de las destrezas insertadas en esta guía para el docente de educación inicial. Sobre la validez de los antes señalado refiere: "El currículo se centra en el reconocimiento de que el desarrollo infantil es integral y contempla todos los aspectos que lo conforman (cognitivos, sociales, psicomotrices, físicos $\mathrm{y}$ afectivos" (MINEDUC, 2016).

En efecto, el documento en estudio fue elaborado por profesionales de la salud, de la neurociencia y pedagogos, por tal motivo solicita al docente utilizar herramientas que impacten la memoria del niño de modo vivencial, así lo refiere cuando según el documento Bienes públicos regionales para la atención de la primera infancia (CEPALGIZ) citado por el (MINEDUC, 2014) "existen períodos críticos o sensibles, en que las redes neuronales tienen una excepcional 
susceptibilidad a los efectos del medio ambiente y la experiencia (interacciones sociales y con objetos).

\section{Música, sonido y percepción}

Para Vargas (1994), la Percepción puede verse alterada por la condición socio cultural del individuo en la vida adulta, de cómo percibe las cosas según las experiencias previas, incluso las experiencias infantiles, sin embargo, en el mismo artículo refiere que las percepciones recibidas durante la infancia, tendrán un lugar en los recuerdos y podrán ser desarrolladas en el cerebro si son manejadas de forma adecuada. En consecuencia Vargas (1994) señala que "cierta lógica de entre varias posibles, que se aprende desde la infancia y que depende de la construcción colectiva y del plano de significación en que se obtiene la experiencia y de donde ésta llega a cobrar sentido" (p. 48).

Vinculado a esa lógica el concepto de percepción estará determinado por los estímulos recibidos, tomando en cuenta quien los emita y en el tiempo y objeto que se proponga para el mismo, de forma tal que este impactará en el recuerdo afectando directamente el proceso cognitivo en zonas específicas del cerebro.

Para tal efecto se identifican los elementos percepción para dar una secuencia de cómo activar el cerebro, el cual es definido según (Jauset, 2018) como: "...órgano que controla y regula el funcionamiento de todo nuestro organismo y es el origen de todas las funciones cognitivas, de las emociones y de los sentimientos" p. 46

Sobre la validez de esta investigación, se infiere la incidencia de la sensopercepción y la música, la cual es definida por la Real Academia Española (RAE) citada por (Jauset, 2018) como: "el arte de combinar los sonidos de la voz humana o de los instrumentos, o de unos y otros a la vez, de suerte que produzcan deleite, conmoviendo la sensibilidad, ya sea alegre, ya tristemente" (p.18).

Por lo tanto, todos estos conceptos propuestos para mejorar la actividad académica con los niños de cuatro años, implican un esfuerzo de lectura conocimiento que beneficiaran a la comunidad estudiantil y a su vez al cuerpo docente conociendo estrategias innovadoras para ser y hacer niños más felices e inteligentes. Dentro de esta investigación se ha analizado el sentido de la búsqueda de información lo cual implica tiempo y esfuerzo, a esto se le llama disciplina, y a su vez de utilizar un recurso artístico para potenciar habilidades cognitivas a través de los sentidos. De esta forma, la autora define la música como: Ciencia artística que implica belleza por ser arte y disciplina por requerir estudio e investigación.

\section{MÉTODO}

El estudio se desarrolló bajo el análisis de la información apoyada en el enfoque cuantitativo debido que se analizó la realidad a través de procedimientos de medición, siendo considerado un proyecto socio educativo, de campo y documental. La población y muestra fue tomada en su totalidad por ser finita, está conformada por diez (10) docentes y veinticinco (25) niños de cuatro (4) años de edad todos del Centro de Educación Inicial Mario Benedetti, ubicado en Quito Ecuador durante el primer semestre del año 2020.

Castillero (2015) manifiesta que el enfoque cualitativo "Se basa en el estudio y análisis de la realidad a través de diferentes procedimientos basados en la medición, es posible realizar experimentos y obtener explicaciones contrastadas a partir de hipótesis" (p. 20), es decir que mediante datos recogidos por medio de encuestas realizadas a las docentes del Centro Educativo. 
Para el análisis de la información se realizó una división en dos secciones, la primera dirigida a los niños de 4 años de edad utilizando la técnica de la observación, la segunda sección usando los instrumentos para la recolección de datos en donde se utilizó Ficha de Observación dirigida, Registro de Observación.

Se aplicó una encuesta cerrada a los docentes de 20 ítems, estructurada en tres partes, la primera con el fin de conocer el nivel de conocimiento sobre Enseñanza musical relacionadas con la sensopercepción, y la segunda parte enfocada en conocer cuál es la realidad de la planificación y actividades relacionadas a través del conocimiento musical y la tercera parte relacionada a capacitaciones.

Los ítems fueron efectuados, codificadas mediante símbolos numéricos elaborados por las investigadoras tomando en cuenta las variables de la investigación. El instrumento fue validado por expertos en educación inicial, a partir de la información obtenida se obtienen los conceptos que tienen las docentes sobre el ejercicio metodológico relacionado con la sensopercepción y la música. Es importante destacar que la realidad particular y tal como lo evidencian los sujetos de esta investigación los resultados fueron graficados y analizados de la siguiente manera:

Esta investigación según los objetivos propuestos fue de carácter descriptivo interpretativo, ya que los datos fueron recogidos de la realidad entre los niños y sus docentes en la recogida de la información. Este proceso de observación permitió analizar las actividades musicales relacionadas con la sensopercepción realizadas por los niños de la mencionada institución infantil.

\section{Registro descriptivo}

\section{RESULTADOS}

Según los registros observados durante un periodo de tres meses (3) se pudo evidenciar que los niños cumplían su rutina diaria con actividades como pintar, salir al parque, actividades en el baño y descanso, sin embargo, no se señalan actividades musicales de ningún tipo.

Se planifican actividades musicales relacionadas con la sensopercepción y el último periodo del trimestre para ser aplicadas dos veces por semana. La aceptación de la inclusión y participación de los niños frente a estas actividades fue sorpresiva, puesto que no están acostumbrados a este tipo de metodologías. A tal efecto, se tiene una aceptación a realizar las actividades como Cantar y tocar instrumentos de percusión, con un $80 \%$ frente a un $20 \%$ que permanece pasivo, se realizaron actividades musicales con canciones cantadas y acompañadas de instrumentos melódicos, donde un $72 \%$ comprenden el significado de la letra de la canción mientras un 28\% no realizan la actividad. Al aplicar las actividades musicales un $100 \%$ mostro alegría al escuchar y ver las actividades propuestas por la investigadora. En la aplicación de actividades de relajación, el $84 \%$ de niños y niñas de 4 años se relaja al escuchar música suave mientras que el $16 \%$ no lo hace.

\section{Encuesta}

\section{Encuesta a los docentes}

\section{Enseñanza musical}

Como resultado al reconocimiento del efecto de la música a través de la sensopercepción el $100 \%$ respondió que sí conoce los beneficios de la música, lo que refleja que los docentes reconocen la importancia de la utilización de actividades musicales sin embargo los docentes en un $80 \%$ utilizan la música dentro de la rutina diaria frente a un $20 \%$ que no la utiliza. Este porcentaje se repite en los docentes que evidencian que a través de 
la música los niños aprenden. Para la utilización de la música a través de la sensopercepción, solo un $40 \%$ a veces lo utiliza y observa que mejora en el rendimiento de los niños, mientras un $60 \%$ afirma que siempre lo hace. El $60 \%$ siempre ha observado que cuando utilizan música en sus actividades el rendimiento de los niños mejora ya sea de forma recreativa o de forma lúdica, mientras que el $40 \%$ durante las actividades musicales a veces evidencia un mejor rendimiento.

\section{Utilización de ambientes musicales}

Es interesante conocer que un $100 \%$ cuenta con el ambiente de música dentro de sus aulas, aunque sin embargo un $20 \%$ no planifica actividades metodológicas para la misma.

\section{Capacitaciones}

Dentro de las respuestas encontradas, las docentes manifiestan que un $20 \%$ nunca ha asistido a charlas sobre música, no utilizan la música ni la percepción con los niños mientras que un $80 \%$ señala que solo a veces realiza estas actividades. El porcentaje baja significativamente, solo el $60 \%$ de docentes a veces utilizan actividades para el desarrollo de la percepción de los niños, mientras que el $40 \%$ nunca ha aplicado actividades de este tipo. El $100 \%$ si les gustaría tener más información acerca de la importancia de la música en el desarrollo cognitivo. Lo que indica que se debe incrementar las charlas o capacitaciones con respecto a la música y la importancia que tiene en los niños y niñas.

Tomando en consideración los resultados de los porcentajes obtenidos a través de la metodología, el objeto de esta investigación denota que el nivel de conocimiento de los docentes de Educación Inicial sobre la incidencia de la música a través de la sensopercepción en niños de 4 años de edad es bajo, ya que a pesar que utilizan la música no es aplicada.

\section{Discusión}

Se ha estudiado principalmente los documentos de política pública otorgados por el Ministerio de Educación ente encargado de vigilar que la educación tenga su mayor eficacia y realce, sobre todo en la educación inicial, edad tierna donde se puede generar un óptimo desarrollo integral.

La preparación del personal docente es un factor determinante para logar metodologías adecuadas relacionadas con el tema, así lo determina un estudio de la autora (Campos, 2020) quien realizó un estudio titulado Estrategias metodológicas y su influencia en el desarrollo de habilidades cognitivas en los niños/as de segundo grado refiere: "la docente a cargo de los niños de segundo grado debe obtener una capacitación didáctica en el conocimiento de nuevas estrategias metodológicas que influencien en el desarrollo de habilidades cognitivas en los niños de segundo grado". (p. III).

Se hace interesante que la música, aunque está relacionada directamente con el proceso formativo de los niños y niñas, está siendo poco utilizado por las docentes en el desarrollo de estrategias metodológicas para estimular el desarrollo integral de los niños, por esta causa la autora fundamenta su estudio creando estrategias metodológicas musicales para la mejor labor educativa, como se evidencia en sus conclusiones.

Respecto a este tema, se pudo evidenciar que el (MINEDUC 2014) contiene dentro de su normativa y organización temas referentes a la sensopercepción, aunado a los estudios de las corrientes pedagógicas de la neuroeducación. Así mismo la música, como elemento ineludible en las actividades diarias con los niños de 0 a 5 años. Tomando en cuenta lo anterior, existe esta disposición por parte de las autoridades gubernamentales que no debe ser obviado.

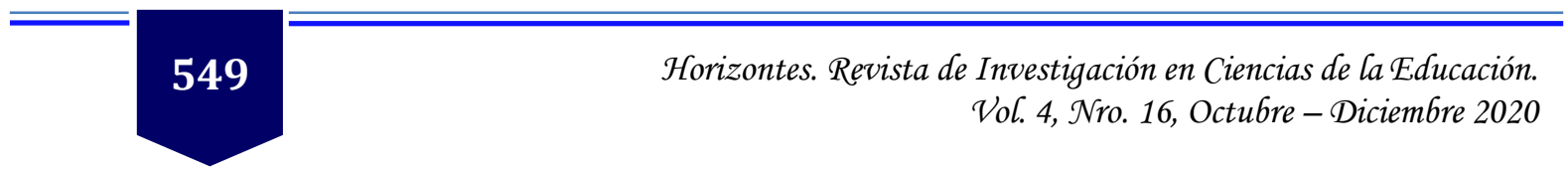


Los estudios realizados por distintos investigadores relacionados con música y sensopercepción, muchos coinciden que los docentes no conocen la eficacia y resultados de al no conocerlas estas actividades no las utilizan, siendo realmente alarmantes, puesto que cada autor recomienda a los docentes leer y preparase sobre el tema, ofreciendo marco teórico actualizado, blogs o guía de actividades para el docente pueda guiarse en la realización de las mismas.

Dentro de este marco se menciona el estudio de Velázquez Bravo (2020) realiza un proyecto de investigación titulado Creciendo con la Música, recursos musicales para trabajar los ámbitos de desarrollo y aprendizaje en el nivel inicial, mencionando dentro de su estudio las limitaciones del docente para desarrollar actividades musicales, al respecto señala:

Tampoco está explorado ni se maneja el tema didáctico musical para edades tempranas, por lo que es necesario buscar nuevas técnicas y recursos mediante los cuales se logre un ambiente agradable y motivador para los niños durante su crecimiento $\mathrm{y}$ aprendizaje (Velázquez Bravo, 2020, p. 11).

Hasta el presente los estudios revisados, aportan la importancia de la preparación y el conocimiento del docente para poder aplicar métodos útiles e innovadores en el proceso de enseñanza aprendizaje, siendo el sonido como producto de la música un elemento al alcance de todos, y recomendable para estimular el desarrollo integral del infante, donde los resultados de esta investigación reflejan que los docentes manifiestan su deseo de estar capacitados para un mejor desarrollo en sus actividades con los niños.

Al respecto, (Quishpe, Gavilanes, Benavides, y Saca, 2017) realizan un estudio en Ecuador titulado Importancia del desarrollo sensoperceptivo en los niños y niñas del nivel inicial dos, trazándose el objetivo de Fundamentar la importancia del desarrollo sensorial en el aprendizaje de los niños, la investigación se realizó a través de una metodología descriptiva, en síntesis se obtuvo como conclusión: "El desarrollo sensoperceptual en los niños en sus primeras edades, está signado por toda la información que capta del mundo exterior a través de los órganos de los sentidos." (p. 10). Como complemento de la relación entre la sensopercepciòn y la música, se hace necesario revisar antecedentes de estudios que puntualicen que tipo de métodos se utilizan para afectar directamente los canales perceptivos a través de la música.

Al hacer la revisión del marco teórico, se comprueba científicamente que el cerebro es el motor de toda la actividad integral del ser humano, y que a través de la estimulación este puede generar sinapsis que se transformaran en más neuronas, lo que traerá como consecuencia niños más inteligentes. $\mathrm{Al}$ mencionar las zonas del cerebro que se activan al ser estimuladas por la sensopercepción, se puede notar que existe una innegable relación entre las partes del cerebro, los sentidos, los canales perceptivos, la música y el currículo.

Al realizar un breve análisis sobre la corteza cerebral donde se ubica la activación del lenguaje, movimiento, vista, gusto, oído, olfato relacionados todos con la amígdala cerebral que es el centro de las emociones, vivifica la gran oportunidad que tienen los docentes de educación inicial de planificar estrategias metodológicas divertidas, innovadoras, musicales donde están involucradas muchos de los ámbitos y destrezas mencionadas en el currículo de educación inicial 2014.

No obstante, todo este conocimiento recopilado a través de este artículo busca llevar a la reflexión a los docentes, padres de familia, y 
toda aquella persona relacionada con el mundo infantil, a indagar sobre los beneficios que trae la música, tan noble, tan apacible y al alcance de cada uno, a través del sonido incluso de la misma naturaleza.

Los resultados de esta investigación cumplen con el objeto de estudio el cual fue identificar que los docentes de Educación (caso Centro Infantil seleccionado) tienen un nivel bajo sobre el conocimiento sobre la incidencia de la música a través de la sensopercepción en niños de cuatro años de edad.

Este estudio tiene el propósito de crear expectativa, preguntas, inquietudes en el lector, con la intención de incluir la música de forma adecuada dentro de las experiencias de aprendizaje planificadas cada día en el rol educativo.

Aun cuando el tiempo que se vive actualmente, año 2020 en Ecuador la mayoría de los Centros Infantiles están cerrados a causa de la Pandemia por el Covid19, el uso de las tics puede emplearse para el uso de este tipo de actividades sin problema alguno, y por ende brindar a los niños que están en confinamiento un momento de relax y de esparcimiento aunado a objetivos claros planteados por el maestro.

\section{CONCLUSIONES}

Al concluir la presente investigación, se puede indicar que el proyecto logro cumplir con el objetivo propuesto, analizando el nivel de conocimiento de los docentes de educación inicial en niños de 4 años sobre la música y la sensopercepción.

Se puede ultimar que el mundo educativo tiene un sin fin de metodologías válidas para la aportar en el proceso de enseñanza aprendizaje de la educación inicial, en especial en niños de cuatro (4) años de edad. Durante el proceso metodológico, se pudo indagar que muchos investigadores están interesados en el tema de la sensopercepción asociado a ámbitos como cultura, expresión de sentimientos y emociones, compromisos auditivos (hipoacusia) y también directamente asociados a la educación musical.

A través de los registros descriptivos, se pudo determinar que los docentes aplican actividades musicales en un porcentaje bajo, y solo para hábitos (comer, dormir, jugar, ordenar entre otros), pero no aplican actividades donde se evidencie la música asociada a los sentidos. La aplicación de actividades dentro del aula de educación inicial es una exigencia por parte del Ministerio de Educación en Ecuador, y docentes realizan mencionadas estrategias, sin embargo esta investigación refleja que solo un $60 \%$ aplica actividades musicales A veces y un $40 \%$ nunca en líneas generales, sin embargo el 100\% de los docentes solicito se formado con herramientas que permitan al niño de cuatro años vivir a través de la educación experiencias relacionadas con la sensopercepción y la música.

Al aplicar algunas actividades de sensopercepción y música a los niños se pudo evidenciar que no todos participaron, se puede asumir que la investigadora no forma parte de su ambiente cotidiano, sin embargo, todos manifestaban alegría al escuchar las canciones y ver realizar los juegos a los niños que accedieron a participar.

El mundo docente está interesado en estar actualizado, por esto es necesario realizar investigaciones detallando la incidencia de la música y la sensopercepción., puesto que, al comunicarse esta información, y ser acogida y puesta en práctica por todo profesional $\mathrm{y}$ padres de familia interesados en ofrecer la mejor estimulación para potenciar capacidades tanto cognitivas como emocionales.

\section{REFERENCIAS}

Alvarado, R. (20 de enero de 2019). ¿Cómo afecta eliminar las clases de música en Primaria? La Vanguardia Vida, pág. 3 
Campos, K. C. (2020). Google Acadèmico. (U. T. Babahoyo, Productor) Obtenido de http://dspace.utb.edu.ec/bitstream/handle /49000/9039/E-UTB-FCJSE-EBAS000262.pdf? sequence $=1$ yisAllowed $=\mathrm{y}$

Castillero, 0. (2015). Psicologíay Mente. Obtenido de https://psicologiaymente.com/miscelanea/ tipos-de-investigacion

Floralba, A., y Villacis. (14 de diciembre de 2018). Google Scholl. doi:2602-8069

Jauset, B. J. (2018). Música Neurociencia. La Musicoterapia. Barcelona: UOC

MINEDUC. (11 de marzo de 2014). Google. Obtenido de https://www.google.com/search?q=curricu lo+de+educacion+inicialyrlz=1C1CHBF_esE C913EC913yoq=curriculo+de+educacion $+\mathrm{i}$ nicialyaqs=chrome..69i57j35i39j0j0i20i263 j014.6335j0j

Quishpe, Gavilanes, Benavides, y Saca. (2017). Google Academico. Obtenido de IMPORTANCIA DEL DESARROLLO SENSOPERCEPTIVO EN LOS NIÑOS Y NIÑAS DEL NIVEL INICIAL DOS: https://scholar.google.com/scholar?hl=esy as_sdt $=0 \% 2 \mathrm{C} 5 \mathrm{yq}=\mathrm{IMPORTANCIA}+\mathrm{DEL}+\mathrm{DE}$ SARROLLO+SENSOPERCEPTIVO+EN+LOS+ $\mathrm{NI} \% \mathrm{C} 3 \% 910 \mathrm{~S}+\mathrm{Y}+\mathrm{NI} \% \mathrm{C} 3 \% 91 \mathrm{AS}+\mathrm{DEL}+\mathrm{NIV}$ EL+INICIAL+DOSybtnG=

Sánchez 0. (2005). Educaciòn Musical y Educaciòn Inicial. En M. d. Deportes. Caracas, Venezuela: MINEDU

UNESCO. (19 de Diciembre de 2012). Educación musical y su importancia. La Hora.

(UNICEF), F. d. (20 de Diciembre de 2020). Google. Obtenido de https://www.unicef.org/costarica/primerainfancia/m\%C3\%BAsica-para-lani\%C3\%B1ez

Vargas, L. M. (1994). Sobre el concepto de percepción. Alteridades, pp. 47-53.

Velázquez Bravo, M. (agosto de 2020). Google Acadèmico. (Pontificia Universidad Catòlica de Ecuador) Recuperado el 12 de noviembre de 2020, de http://repositorio.puce.edu.ec/handle/220 $00 / 18149$ 